\title{
Human pollution: too many people
}

\author{
M. H. Saier Jr. • J. T. Trevors
}

Published online: 3 April 2010

(C) Springer Science+Business Media, LLC 2010

Today's media have revealed a keen interest of Americans in the issue of immigration, particularly from Central and South America into the United States. In fact, this topic has created heated debate, but it is not new. Human migrations have occurred throughout history, ever since Homo sapiens left Africa. To understand this phenomenon, one must understand simple diffusional theory, which is applicable to molecules, cells, people, pollutants, etc. The rate of flux, or the net number of people crossing the border per unit time $(\mathrm{d} P / \mathrm{d} T)$, is proportional to the driving force for migration $(F)$ times the population $(P)$. In mathematical terms, $\mathrm{d} P / \mathrm{d} T=k(F \times P)$ where $k$ is a constant. The force, $F$, is a measure of the difference between the quality of life on one side of the border and that on the other side, and the population reflects the number of people who live on the side of the border from which the migration occurs. Given the immutability of this equation, how can the flux be controlled? There are only three answers: (1) equalize the standard of living of the people on the two sides of the border, (2) decrease the population on the side from which the people are coming and (3) change $k$. Does the United States have the capability to bring about one or all of these changes? What would be necessary to do so?

To accelerate the standard of living equalization, we suggest the U.S. divert a significant proportion of its GNP for non-military aid $(0.7 \%$ as recommended by the

\author{
M. H. Saier Jr. ( $₫)$ \\ Biological Sciences, University of California at San Diego, \\ La Jolla, CA 92093-0116, USA \\ e-mail: msaier@ucsd.edu \\ J. T. Trevors $(\bowtie)$ \\ Department of Environmental Biology, University of Guelph, \\ Guelph, ON N1G 2W1, Canada \\ e-mail: jtrevors@uoguelph.ca
}

U.N. instead of the $0.14 \%$ now provided by the U.S., the smallest percentage of any of the developed nations), to help mange the reduction in the human population. The objective is to provide birth control to all nations worldwide, especially countries where it is currently not properly available. Abstinence programs simply do not work, as revealed in hundreds of international studies, and this would cost the U.S. a mere $\$ 40$ billion per year, nothing in comparison to the $>\$ 1,000$ billion already spent in Iraq over the past 3 years. Thus, there is hope. All we need is rational, capable, diplomatic government policies to ensure such a program is successful.

Human pollution of the biosphere is the most devastating form of pollution. There are simply too many humans consuming too much of the finite non-renewable resources on the Earth. Human pollution is the cause of virtually all other forms of pollution. Humans need to immediately embark on a renaissance in their intellectual activities. Inferior ideas and activities must be replaced with superior ideas and activities. Global problems must be replaced with global solutions. Greed and discrimination must be replaced with sharing and mutual living and tolerance. The human objective is not to populate the Earth with too many humans. Equalization of human living conditions is only possible with a smaller human population. A human intellectual renaissance is desperately needed to place humanity on the correct path today and into the future. Otherwise, humans are relying on a false sense of security if they think that technical solutions will ensure a quality future for humanity. This is wishful thinking or an exercise in human imagination, if the current generation imagines that future generations will be living in a better world. Global climate change alone partly caused by too many humans and their activities will ensure future generations will have a much-reduced quality of life. 